\title{
TÉCNICA DE EDICIÓN \\ DE GENES CRISPR/CAS9. \\ RETOS JURÍDICOS PARA SU REGULACIÓN \\ Y USO EN COLOMBIA
}

NATALIA LAMPREA BERMÚDEZ*

ÓSCAR LIZARAZO-CORTÉS**

\section{INTRODUCCIÓN}

Nunca había sido tan sencillo editar genes, la tecnología CRISPR/Cas9 lo hace posible con un sistema biológico muy sencillo y con gran potencial en materia de salud, agricultura, bioindustria, etc. Es una tecnología capaz de identificar y reparar las secuencias de DNA defectuosas en pacientes que sufren enfermedades de origen genético, tales como Huntington o diabetes tipo I. Sirve también para prevenir y controlar las infecciones virales tales como VIH o hepatitis. Así mismo, puede ser usada en microorganismos y también en plantas o animales para eliminar características no deseables del fenotipo, incluso cuando el organismo es adulto. Estas son, entre otras, las aplicaciones que tiene el sistema CRISPR/Cas9, y dan una idea de su gran potencial. Se trata de una herramienta tan sencilla y económica que puede ser usada por cualquier persona que conozca de biología molecular, por lo que su efecto, en palabras de la investigadora Dana Carroll, es que ha "democratizado la

\footnotetext{
* Bióloga y magíster en Biología-Genética de la Universidad Nacional de Colombia. Especialista en Propiedad Industrial, Derecho de Autor y Nuevas Tecnologías de la Universidad Externado de Colombia. Asesora de patentes, independiente. Contacto: [natalia. lamprea@gmail.com].

** Abogado de la Universidad Nacional de Colombia. Magíster en Propiedad Intelectual de Université-Paris Sud xi y Université París I-Panthéon Sorbonne. Candidato a PhD. Profesor de la Facultad de Derecho de la Universidad Nacional de Colombia. Director del Grupo de Investigación Plebio. Contacto: [oalizarazoc@unal.edu.co].

El segundo autor presentó una oposición a la solicitud de patente de CRISPR/Cas9 en Colombia, individualmente, como persona natural y con fines académicos, "amicus curiae". Fecha de recepción: 2 de marzo de 2016. Fecha de aceptación: 27 de julio de 2016. Para citar el artículo: Lamprea Bermúdez, N. y Lizarazo-Cortés, Ó. Técnica de edición de genes CRISPR/Cas9. Retos jurídicos para su regulación y uso en Colombia. Revista La Propiedad Inmaterial n.o 21, Universidad Externado de Colombia, enero-junio 2016, pp. 79-110. DOI: http://dx.doi.org/10.18601/16571959.n21.04.
} 
edición de genes" (Travis, 2015). Sin embargo, estas posibilidades no están exentas de interrogantes bioéticos, en particular al aplicar esta técnica en humanos.

El propósito de este artículo es explicar de forma sencilla el funcionamiento biológico del sistema: ¿cómo funciona?, ¿qué lo hace tan atractivo y "mejor" que otras herramientas de edición de genes existentes? Posteriormente, se ofrece un panorama sobre sus posibles aplicaciones, desde un punto de vista teórico y práctico, pues ya se ha aplicado en varios campos generando cientos de artículos y de solicitudes de patente; es decir, se trata de responder a la pregunta: ¿para qué sirve? Luego se incluyen algunas consideraciones bioéticas sucintas por la aplicación de CRISPR/Cas9 en humanos, particularmente en línea germinal humana. También se analizan la solicitud de patente en trámite en Colombia y los aspectos a considerar en su examen. Finalmente, se realiza una primera aproximación al panorama regulatorio de acuerdo con el uso de la tecnología en modificación de genes de origen humano, o modificación de genes no humanos, para dejar así un esbozo del posible uso de la tecnología en Colombia.

\section{FunCIONAMIENTO Biológico DEL SISTEMA}

En el campo de la ingeniería genética, siempre fue un reto poder "identificar" un sitio específico del DNA y poder editarlo al mismo tiempo, por ejemplo, para poder eliminar toda una variante defectuosa de un gen o cambiar una mutación puntual que impide la formación de una proteína. CRISPR/Cas9 logra justamente eso, identificar un segmento específico de DNA y eliminarlo o reemplazarlo, usando siempre las mismas herramientas: un segmento-guía que es un RNA con la copia del DNA que se debe identificar (RNA guía), y unas tijeras que es la proteína Caspasa 9 (Cas9) que corta el segmento específico de DNA (actividad endonucleasa) y que separa la doble hélice de DNA para abrir sus hebras y así poder editarlas (actividad helicasa). Además, hay un tercer elemento que aunque no es tan mencionado, es fundamental en la tecnología: una secuencia corta (PAM) que se unirá al DNA y estabilizará la proteína Cas9 (Doudna y Charpentier, 2014; Wright et al., 2016; Mesa, 2015).

La forma como se enlazan estos elementos también es muy sencilla, pues la proteína Cas9 es guiada por el RNA-guía al sitio deseado en el DNA para que lo edite, separando y cortando las dos hebras de DNA, mientras que la secuencia PAM se ubica en el DNA para estabilizar el punto de corte de la secuencia. Así, con solo estos elementos se elimina o modifica el DNA defectuoso o no deseado (DoudNA y Charpentier, 2014). Cada vez que se quiera emplear la tecnología CRISPR/ Cas9 para realizar una nueva modificación, lo único que se necesita es tener el RNA del gen blanco de interés; la secuencia PAM y la proteína Cas9 son siempre las mismas, independientemente del DNA que se quiera editar. Esto es justamente lo que representa el avance más importante de esta tecnología, su sencillez, pues no requiere ni de diseño de proteínas ni de aparatos enzimáticos complejos para lograr llegar y editar un segmento específico de DNA. 
Las tecnologías de edición de genes alternativas, tales como las nucleasas de dedos de zinc (ZFN) y las nucleasas efectoras de activador de transcripción (TALEN), requieren moléculas más complejas para desarrollar la edición, especialmente en lo relacionado con el diseño de proteínas específicas para realizar cada evento de edición, por lo que su uso ha sido limitado, costoso y no se ha podido utilizar como herramienta estándar para la edición genética (GAJ et al., 2013; Hsu et al., 2014).

El sistema CRISPR/Cas9, con su RNA como molécula guía que dirige la actividad de Cas9, fue descubierto en 2012 en las bacterias; es el sistema inmune de estas y es empleado para defenderse del ingreso de virus y plásmidos (JiNeK et al., 2012). Cuando un virus infecta a una bacteria, lo que hace es ingresar a la célula bacterial e insertar su DNA en el de esta, usar la maquinaria de replicación de la bacteria para reproducirse y crear más virus. El sistema CRISPR/Cas9 les permite a las bacterias que han sido infectadas por un virus identificar el DNA viral y enviar un fragmento de este a una "biblioteca", esto es, un arreglo de DNA con secuencias cortas palíndromas repetidas separadas por espacios (Clustered Regularly Interspaced Palindromic Repeats - CRISPR) donde se ubica el DNA invasor viral. Cuando la bacteria es nuevamente atacada por ese virus, se defiende tomando de la "biblioteca" la secuencia del DNA viral, transcribiendo o replicando el RNA con esa secuencia invasora, para identificar ese mismo segmento viral en cualquier parte de su DNA bacterial donde se haya insertado, dirigiendo junto al RNA a la proteína Cas9 para que corte el DNA viral y lo elimine, evitando así que el virus se pueda replicar y afectar de nuevo a la célula bacterial (MAKAROva et al., 2011).

A partir de este sistema CRISPR/Cas9 bacterial se realizaron versiones ligeramente adaptadas que permiten la edición del DNA en eucariotas -aquellos organismos que tienen membrana nuclear definida, tales como insectos, mamíferos, plantas, etc.-, puesto que en estos, una vez la secuencia blanco del DNA es eliminada, el organismo tiene diferentes formas para reparar el DNA. Este sistema de reparación del DNA permite que la tecnología, además de identificar y eliminar el DNA defectuoso, pueda modificarlo, reemplazándolo por una copia de DNA sin defectos o con una característica deseable.

Con esta tecnología tan sencilla se puede realizar la modificación del DNA de cualquier organismo, hacerlo in vivo y realizar la modificación en cualquier etapa de su vida, o etapa celular, desde las células somáticas o células adultas diferenciadas hasta las células gaméticas o germinales, incluyendo también la etapa de cigoto o embrión. Es decir, no solo se puede "arreglar" el DNA del individuo en etapa adulta, sino que incluso se puede transmitir este "arreglo" o nueva característica a su progenie.

\section{Aplicaciones del sistema CRISPR/Cas9}

A partir del descubrimiento de CRISPR/Cas9 en el año 2012, las investigaciones y aplicaciones de la tecnología han crecido de manera exponencial. Se han desarrollado 
ensayos con el sistema para múltiples aplicaciones, por ejemplo en enfermedades genéticas, imágenes de diagnóstico, modificaciones genéticas en insectos, plantas, entre otros. A continuación se mencionan algunas de las aplicaciones destacadas logradas para diferentes organismos y áreas.

En animales, se ha utilizado para eliminar cataratas causadas por una mutación dominante en el gen Crygc en ratones, logrando que este renovara el tejido a uno sano, desapareciendo parcialmente la catarata, y que la descendencia del roedor no tuviera la enfermedad (Wu et al., 2013). Además, en ratones adultos con distrofia muscular de Duchenne se probó la reparación del gen de distrofina, usando el sistema inyectado directamente en el tejido muscular o a través del flujo sanguíneo, logrando en ambos casos una mejora del tejido muscular (TABEBORDBAR et al., 2015). La reparación de la distrofia muscular también se logró a partir de la edición en la línea germinal de ratones afectados con la enfermedad (Long et al., 2014).

Otra línea de desarrollo ha sido el impulso genético o reacción en cadena genética (conocida como gene drive) que ha permitido modificar mosquitos Anopheles stephensi hembra de manera que no puedan transmitir el patógeno de la malaria, haciendo que la modificación se disperse más rápido en la población al usar, además de la distribución mendeliana, la fijación del gen editado al colocar CRISPR/ Cas9 dirigido a los genes no editados en los individuos desarrollados (GANTZ et al., 2015). También se han modificado las hembras de Anopheles gambiae con genes de infertilidad, que son heredados de manera super-mendeliana gracias al CRISPR/ Cas9 dirigido a interrumpir los genes normales que no se habían modificado; los resultados de transmisión a la progenie del gen modificado son del 91 al 99.6\% (Hammond A. et al., 2016). Obsérvese que en cualquiera de las dos aproximaciones el resultado a corto plazo es que se diezma o se acaba la población de Anopheles $s p$. Esta línea de trabajo sobre impulso genético ha causado preocupación por los resultados a corto plazo sobre el equilibrio de las poblaciones y, más importante aún, sobre el efecto en la cadena alimenticia y el equilibrio en el ecosistema, al modificar drásticamente la distribución de una especie en un ambiente.

En plantas, se ha realizado edición genética exitosa en modelos como Nicotiana tabacum y Arabidopsis, y en especies de cultivo como arroz, trigo, maíz, sorgo, tomate y naranja (Jiang et al., 2013; Belhaj et al., 2015; Shang et al., 2014). En plantas modelo se ha observado que, pese a la naturaleza poliploide (varias copias del mismo cromosoma por planta), las mutaciones son heredadas de manera homocigótica o bialélica en la primera generación, lo que muestra una modificación altamente eficiente para lograr la estabilidad genética en el tejido y la transmisión de la característica deseada en la descendencia (Belhaj et al., 2015). También se desarrolló un arroz resistente a herbicida (Sun et al., 2016). Estos desarrollos generan el debate sobre si a estas plantas se les aplica o no la reglamentación sobre OGM, como se menciona más adelante.

En humanos, se reparó in vitro un gen defectuoso en células madre intestinales aisladas de pacientes con fibrosis quística (SchWANK et al., 2013); se han realiza- 
do pruebas de imágenes diagnósticas en genes de interés al incluir proteínas de fluorescencia en el RNA-guía (CHEN et al., 2013). Así mismo, se ha podido realizar screening genético o barrido genético en células humanas, para identificar la función de cada gen en segmentos determinados del DNA, pudiendo apagar uno a uno los genes, haciéndolo incluso en genes no codificadores de proteínas (WANG et al., 2014). Este último punto hace que CRISPR/Cas9 supere los ensayos realizados con técnicas alternativas tal como el RNA de interferencia (IRNA), que solo permite establecer funciones de genes codificadores de proteínas.

En el campo de la virología, se ha logrado la supresión de la infección del virus de la hepatitis B en cultivos in vitro de hepatocitos humanos (Kennedy et al., 2015), la erradicación del genoma viral en células con infección latente de VIH y la prevención de nueva infección por este virus viH-1 (Hu et al., 2014). Además, se ha logrado la erradicación de retrovirus del genoma de cerdo, lo que podría ser una mejora en el trasplante de órganos de origen animal (Travis, 2015).

Pero la aplicación más debatida bioética y jurídicamente hasta el momento es, sin duda, el estudio realizado por investigadores chinos en cigotos humanos no viables (cigotos tripronucleares). Los cigotos tenían alteraciones en el gen de la $\beta$-globina (desarrollando la enfermedad conocida como $\beta$-talasemia); las modificaciones mostraron una baja tasa de reparación del DNA defectuoso (un total de 39\% eventos de reparación), efecto mosaico en algunos embriones y modificaciones no deseadas en otras regiones del DNA (off-target DNA), por lo que el grupo de investigadores sugiere que se requiere un mejor conocimiento del sistema para lograr la edición efectiva en embriones humanos (Liang et al., 2015).

Los campos de aplicación de CRISPR/Cas9 en humanos están en desarrollo y su proyección es alentadora. Funciona como transportador y liberador de medicamentos en células de interés como son las células con cáncer, lo que se ha logrado gracias a una caspasa modificada que tiene actividad para identificar el DNA específico, pero no lo corta (denominada dead-Cas) (Hsu et al., 2014). Asimismo, será protagonista en el diseño de drogas por su actividad como modulador de la expresión de genes; por ello ya compañías farmacéuticas como Astrazeneca y Novartis han invertido en la herramienta.

Un aspecto importante para la expansión de la tecnología es que se ha creado un depósito de plásmidos sin ánimo de lucro con los componentes principales para usarla; estos contienen el gen de la Cas9 y la secuencia PAM, para que cualquier grupo de investigación pueda realizar ensayos con la técnica. Esta iniciativa es de Addgene y está respaldada por los principales investigadores en el área ${ }^{1}$.

Todas estas aplicaciones se han alcanzado a solo dos años y medio de haberse conocido la tecnología, lo que deja ver la facilidad, el gran potencial que tiene CRISPR/Cas para editar o modular el DNA, haciéndolo in vivo y en cualquier tipo de organismo (Hsu et al., 2014). De ahí que sea el momento de hablar de la edición

1. Addgene, página web: [www.addgene.org/crispr/]. 
genética, de sus expectativas, limitaciones y regulación jurídica, porque ahora es una realidad.

\section{Debate BioÉTiCo AlREDEdor De LA TECNOLOGÍA}

Con el escenario logrado en tan poco tiempo, las aplicaciones realizadas y potenciales del sistema de edición de genes CRISPR/Cas9, las preguntas que siempre rodean a este tipo de tecnologías están empezando a responderse. En mayo de 2015, los investigadores rumoraban que se estaba realizado edición genética en embriones humanos, y así fue, el grupo de LIANG y colaboradores en China hizo ese primer ensayo. En el experimento se utilizan cigotos tripronucleares, es decir, fecundados por dos espermatozoides en lugar de por uno, y los cigotos son "fabricados en el laboratorio". Estos empiezan la división celular pero no superan la etapa de 14 días de desarrollo, por lo que los investigadores postularon que son un buen modelo para el estudio de la edición genética (Liang et al., 2015).

Este hecho suscitó una cascada de eventos que reunió a la comunidad científica, la cual ahora está dando sus primeros pasos en materia de criterios para la regulación.

En primer lugar, ante el rumor de la investigación, revistas de primer nivel, específicamente Nature y Science, decidieron no publicar los resultados del grupo de Liang (ZhaI, 2016), y en cambio dieron espacio en sus ediciones para que se hablara sobre los aspectos éticos y técnicos que debían considerarse en el uso de la tecnología en humanos; esta posición fue liderada por varios investigadores destacados en el área (BALtimore et al., 2015).

En segundo lugar, la comunidad científica realizó reuniones internacionales para hablar acerca de la tecnología, tales como el encuentro del Valle de Napa (enero de 2015) y el "International Summit on Human Gene Editing" (diciembre de 2015). Este último reunió a las academias de ciencias, ingeniería y medicina de Estados Unidos, Reino Unido, China y otros países. En el evento, que fue transmitido en vivo, los principales investigadores del área, incluidos aquellos que descubrieron la técnica y aquellos que ya la habían usado en embriones humanos, así como bioeticistas, abogados y otros, expusieron sus puntos de vista sobre las precauciones que se deben tener para el uso en humanos.

Para este momento ya se observaban algunos puntos comunes respecto a la regulación de la tecnología; por ejemplo, Jennifer Doudna y George Church, ambos reconocidos investigadores en CRISPR/Cas9, consideraron impráctica la prohibición total de la ingeniería genética en humanos, dada la facilidad y accesibilidad de la técnica para los científicos de cualquier latitud. Pero también se observan puntos de distanciamiento entre ellos; así, Doudna, investigadora protagonista en el descubrimiento de la tecnología, en su momento solicitó a la comunidad científica una moratoria para la implementación de la técnica en línea germinal y embriones humanos. Debe destacarse que la moratoria se sustentaba no en aspectos morales, sino en aspectos técnicos, pues se esgrimían argumentos sobre la falta de 
conocimiento de la especificidad y precisión de la técnica, en especial en lo que se refiere a las especificaciones del RNA-guía, el riesgo de modificaciones off-target y la necesidad de conocer el efecto de la edición en células y tejidos complejos (Doudna, 2015). Por el contrario, George Church considera que la edición en la línea germinal puede realizarse, dado que los efectos indeseados son poco probables y podrían ser reversibles. Menciona que "los errores en edición ocurren menos de 1 por cada 300 trillones de pares de bases", y que las mejoras de la técnica respecto a las posibles modificaciones off-target hacen que este riesgo baje aún más. De otra parte, menciona que antes que enfatizar en los riesgos deben tenerse en cuenta los beneficios en los tratamientos médicos que podrían alcanzarse. Considera que la prohibición de la edición genética en embriones podría conducir a un mercado negro y al turismo médico no controlado, en aquellas jurisdicciones donde los ensayos en embriones no tienen tantas restricciones legales ( $\mathrm{CHURCH}, 2015)$.

$\mathrm{Al}$ término de esta reunión internacional se formularon conclusiones en cuatro aspectos $^{2}:$ 1) la necesaria investigación básica y preclínica en la edición de genes en humanos está sujeta a reglas legales, éticas y de seguimiento adecuadas. Además, "si en el proceso de investigación, embriones humanos tempranos o células de la línea germinal se someten a edición de genes, las células modificadas no deben ser utilizados para establecer un embarazo"; 2) la posible realización de edición de genes en células somáticas con el propósito de realizar aplicaciones clínicas, realizando ensayos clínicos con un marco regulatorio adecuado y sopesando los riesgos y potenciales beneficios de los ensayos clínicos y terapias a probar; 3) la limitación de la edición de genes en células de la línea germinal o embriones, por lo menos hasta tanto no se hayan evaluado los temas de seguridad y eficacia de las técnicas, y "haya un consenso social sobre la idoneidad de la aplicación”. Se plantea una revisión periódica de este tema; 4) la necesidad de foros continuos, pues cada jurisdicción tiene la "autoridad para regular las actividades bajo su jurisdicción, pero el genoma humano es compartido entre todas las naciones. La comunidad internacional debe esforzarse por establecer normas relativas a usos aceptables de la edición de la línea germinal humana y armonizar los reglamentos, con el fin de desalentar las actividades inaceptables mientras se avanza en la salud y el bienestar humanos".

Si bien estos lineamientos no son vinculantes, ni de obligatorio cumplimiento para un investigador en ciencias biológicas y biomédicas, lo cierto es que deberían ser parámetros a analizar por las autoridades nacionales en medicamentos, salud o comités éticos para pruebas clínicas, con el propósito de que todas las naciones tengan una reglamentación mínima a este respecto. Este es un aspecto que también mencionan los científicos, pues la regulación laxa en algunos países, especialmente aquellos en vías de desarrollo, puede promover el uso "desordenado o indebido" de la tecnología de edición de genes.

2. On Human Gene Editing: International Summit Statement [www8.nationalacademies.org/ onpinews/newsitem.aspx?RecordID=12032015a]. 
Pese a estos lineamientos, algunos países han decidido seguir adelante con la investigación en embriones. Por ejemplo, en Reino Unido la Autoridad sobre Fertilización Humana y Embriología (HFEA, por sus siglas en inglés) ya dio la primera autorización al Instituto Francis Crick para investigar los genes que intervienen en el desarrollo temprano de embriones usando la técnica CRISPR/Cas9, estudiando así las causas de los abortos tempranos (SiddiQue, 2016).

Por su parte, China ya publicó un segundo ensayo con uso de cigotos tripronucleares para probar resistencia a VIH (KANG, 2016). Algunos medios de comunicación sostienen que la postura de China en investigación sobre edición genética en humanos es diferente a la que hay en los países occidentales, porque tienen una regulación laxa, insinuando que allí algunos investigadores tienen la postura de "hacer primero, preguntar después", o que incluso la postura científica de editar los cigotos o embriones no implica problemas éticos puesto que en el pensamiento de Confucio "alguien se hace persona después de nacer" (Kirsten, 2016). Sin embargo, también se ha conocido a través de miembros del Comité Nacional de Ética Médica que esta postura no es tan distinta a la de países desarrollados, indicando que en China las investigaciones sobre genética en humanos utilizan el consentimiento informado para la inclusión de pacientes o muestras en los ensayos, los cigotos modificados no pueden ser utilizados para reproducción y "cumplen con la guía internacional de investigación en embriones humanos de destruir los cigotos poco tiempo después de la modificación (14 días para las guías de Estados Unidos)"; así como que hay regulación específica en el tema de investigación biomédica y reproducción artificial (ZHAI, 2016).

Algunos han sugerido que lo que se requiere es una regulación internacional en el tema, con directrices específicas y mínimas para experimentación con embriones, trabajada desde entidades como la OMs o la ONU (ZHAI, 2016). Otros simplemente sugieren que las técnicas nuevas de edición y reproducción deben iniciar su uso, pues siempre habrá un riesgo en el inicio de su implementación, reflejado en el desconocimiento de los efectos futuros de los embriones concebidos o los factores no considerados, pero que igual los métodos naturales de reproducción causan riesgos y enfermedades, que no son pocos y que requieren ser superados (Harris, 2016).

\section{Patente en trámite en Colombia}

Este apartado analiza el estado de una de las principales solicitudes de patente sobre la tecnología CRISPR/Cas9 presentada en Colombia. Sin embargo, se hace una breve mención al estado de las principales solicitudes de patente de la tecnología en otras jurisdicciones, justamente para ilustrar la importancia de la solicitud tramitada en Colombia.

Mucho se ha mencionado acerca del conflicto de patentes alrededor de la tecnología CRISPR/Cas9 en Estados Unidos, que fue donde apareció dicha tecnología (Regalado, 2014; Sherkow, 2015), y últimamente también en Europa. Hay dos 
solicitudes de patente que han generado el conflicto más relevante y publicitado (Lash, 2014 y 2015; Sherkow, 2016), que corresponden a las dos primeras solicitudes que divulgan el sistema CRISPR/Cas9 completo para la edición de genes, a saber, la solicitud de patente de la Universidad de California, la Universidad de Viena y Jennifer Doudna (рст/US2013/032589), y la del investigador Feng ZHANG (US8,697,359), siendo en este caso sus titulares The Broad Institute, Inc. y Massachusetts Institute of Technology.

La solicitud de ZHANG fue presentada el 15 de octubre de 2013 ante la Oficina de Patentes de Estados Unidos (USPTO), siendo estudiada por vía rápida (fast-track), por lo que su estudio y concesión (15 de abril de 2014) fueron anterioriores a los de la solicitud de Doudna y Charpentier, pese a que su prioridad es posterior a esta (Sherkow, 2015). La solicitud de Doudna y Charpentier a marzo de 2016 continuaba en trámite ante la UsPTO. Ambas solicitudes incluyen la protección del sistema básico de funcionamiento del CRISPR/Cas9 y varias de sus aplicaciones generales en la modificación de expresión de genes en células.

Ante la Oficina de Patentes Europea (EPO) la situación no es diferente: la patente de ZHANG ya fue concedida (EP2764103) y tiene al menos nueve oposiciones que están en estudio, varias de ellas presentadas por anónimos y con argumentos relacionados con incumplimiento de requisitos de patentabilidad frente a lo conocido en el estado de la técnica, y argumentos sobre orden público y moral.

Posterior a estas dos solicitudes básicas de la tecnología hay varias solicitudes concedidas en Estados Unidos y en fase internacional vía PCT, que protegen métodos para tratar enfermedades específicas usando CRISPR/Cas9, la mayoría de ellas presentadas por The Broad Institute y su inventor Fen Zhang, y todas ellas estudiadas en la usPTo por vía rápida (Sherkow, 2016).

La Universidad de California en Berkeley (Doudna) inició un proceso de interferencia a las patentes concedidas a ZHANG, que deberá definir quién es el titular de la tecnología. Esta interferencia interpuesta por la Universidad de California muestra la importancia de estas dos solicitudes de patente y destaca el gran potencial de la solicitud de patente de Doudna, a pesar de no haber sido concedida aún en Estados Unidos y Europa.

En Colombia se presentó una de las principales solicitudes de patente para CRISPR/Cas9. El 25 de noviembre de 2014 se radicó ante la sic la fase nacional de la solicitud de patente de Doudna (РСт/US2013/032589, WO2013/176772), que corresponde al expediente colombiano 14-259531 y contiene las mismas 155 reivindicaciones de la solicitud PCT (LAMPREA y Lizarazo, 2015).

La solicitud de patente que tiene como co-inventoras a Jennifer Doudna y Emmanuelle Charpentier está relacionada con la edición de genomas por el uso de CRISPR/Cas9; fue presentada por primera vez ante la uspTo el 15 de marzo de 2013 y tiene fecha de prioridad del 25 de mayo de 2012 (рСт/US2013/032589) 3 .

3. Con publicación internacional WO2013/176772. 
Los solicitantes son la Universidad de California y la Universidad de Viena. Dicha solicitud de patente reclama el sistema RNA dirigido a ADN con cada uno de sus elementos, secuencia PAM, sgRNA y Cas9 con diferentes secuencias alternativas (reivindicaciones 1-6); vectores de expresión con diferentes variantes de estos elementos (reivindicaciones 7-17); células transgénicas y organismos transgénicos expresando el sistema CRISPR/Cas9 con diferentes variantes (Rv 38-43), composiciones que contienen el sistema CRISPR/Cas9 (Rv 44-63); método de modificación del ADN sitio-específica con múltiples genes posibles a modificar por disminución o por incremento de su expresión (Rv 64-94), modificación por métodos in vitro o in vivo (Rv 95-96), método de tratamiento de sujetos por sistema CRISPR/Cas (Rv 97-108); y kit que contiene distintas variantes del sistema CRISPR/Cas9 (Rv 109-155).

Obsérvese que aunque la solicitud de la Universidad de California no menciona de manera explícita en todas sus reivindicaciones que el método permite la modificación de células germinales o modificación de embriones humanos, tales aplicaciones son en ambos casos posibles, debido a que los métodos reclamados conciben la edición de genes presentes en todo tipo de células. Por ello, la interpretación que debe hacerse es en el sentido biológico, y este incluye este tipo de células. Adicionalmente, hay varias reivindicaciones que sí se refieren específicamente a células germinales modificadas, células humanas, células animales, etc., así como a los métodos para modificar estas células.

De otra parte, aunque los autores realizaron la búsqueda de solicitudes de patente presentadas en Colombia en la base de datos de la sic, no se encuentra reportada ninguna de las solicitudes correspondientes a The Broad Institute cuyo inventor es Feng Zhang, el otro investigador que está en la controversia por la titularidad de la tecnología de edición de genes en Estados Unidos y en Europa. Sin embargo, la base de datos de la sic no registra las solicitudes que aún no han sido publicadas, por lo que es posible que eventualmente en el último año y medio hayan ingresado solicitudes de este solicitante y que no se puedan visualizar.

\section{EXCEPCIÓN PARA LA INVESTIGACIÓN Y EXPERIMENTACIÓN}

De concederse todas las reivindicaciones de esta solicitud de patente de Doudna, toda investigación que pretenda usar el sistema CRISPR/Cas9 con fines comerciales deberá obtener licencia de los titulares. Las investigaciones puramente académicas, con fines de investigación, o experimentación en el laboratorio, sin fines comerciales, podrían beneficiarse de la excepción prevista en la Decisión 486 (art. 53). Es decir, mientras no tengan fines comerciales, nuestros investigadores podrán investigar con la tecnología, aun cuando se conceda la patente. Sin embargo, muchos de los proyectos de regalías o aquellos enmarcados en una relación Universidad-Empresa, no se verían amparados por esta excepción y tendrían que contar con licencia del titular.

A nivel mundial algunos países, incluyendo aquellos de la CAN, cuentan con una excepción de experimentación prevista expresamente. Otros, como Estados 
Unidos, no consagran estatutariamente una excepción de experimentación o investigación, pero por vía jurisprudencial admiten que se use como argumento para eximirse de responsabilidad en juicios por infracción, siempre y cuando los usos sean netamente no comerciales o filosóficos (Mueller, 2001); esto reduce considerablemente el alcance del argumento. Todo lo anterior es particularmente relevante cuando se emplean no solo productos o procedimientos biotecnológicos, sino en especial técnicas o herramientas básicas de investigación tales como ADN recombinante, PCR, y ahora herramientas de edición de genes, particularmente CRISPR/Cas9. Para un análisis reciente y de derecho comparado de las excepciones de investigación/experimentación pueden consultarse, entre otros, cuestionarios y estudios preparados por la Secretaría de la OMPI .

Será necesario que universidades, centros de investigación y empresas biotecnológicas hagan seguimiento al estudio de la solicitud ante la sic, con el fin de conocer qué materia queda protegida y, de ser posible, apoyar el estudio de patentabilidad presentando información que le sea útil a la sic para establecer correctamente el estado de la técnica; esta información ya no se valoraría como oposición, pues esta etapa del trámite ya ha sido superada, pero aun así resulta útil presentar información relevante para el estudio de patentabilidad de la solicitud.

Por ello, entre otras opciones, los investigadores y empresarios deben estar dispuestos a obtener licencias para poder desarrollar sus actividades legalmente. Esto seguramente generará algo de dificultad en los primeros proyectos que usen la tecnología CRISPR/ Cas9, pues nuestros investigadores o universidades no están acostumbrados a tener que pedir licencia para usar una técnica de laboratorio. En Colombia no se solicitaron las patentes iniciales de las tecnologías de ADN recombinantes ni de PCR, lo que confirió amplia libertad de operación a investigadores nacionales, pues además de estar amparadas por la excepción de investigación prevista en la Decisión 486 y anteriormente por las decisiones 344, 313 y 311 artículo 35 literal c), debido al principio de territorialidad de las patentes podían emprender legalmente actividades con fines aplicados y comerciales sin infringir patente alguna. De concederse la patente para la tecnología CRISPR/Cas9, posiblemente será la primera vez que nuestros investigadores requieran realizar el proceso de solicitar una licencia al titular de una patente, y que las universidades, centros de investigación y empresas en biotecnología tengan que asumir el sobrecosto que esto acarrea.

La generación de nuevas solicitudes de patente enfocadas a aplicaciones específicas de la tecnología, y su posible entrada a trámite en Colombia, hace que sea posible que en el caso CRISPR/Cas9, en un futuro próximo, se requieran varias licencias de diferentes titulares. Los interesados en usar la tecnología deberán hacer vigilancia de las solicitudes que inicien trámite en Colombia.

4. wipo, SCP, Standing Committee on the Law of Patents Twentieth Session Geneva, January 27 to $31,2014$.

Exceptions and Limitations to Patent Rights: Experimental Use And/or Scientific Research

Document prepared by the Secretariat [www.wipo.int/edocs/mdocs/patent_policy/en/ scp_20/scp_20_4.pdf]. 
Adicionalmente, debe tenerse presente que hay varios grupos de investigación y empresas que habían publicado previamente resultados de investigación relacionados con el funcionamiento de la Cas9 y sus aplicaciones en la edición de genes (Granahan y Loughran, 2014). Por ejemplo, la solicitud de Danisco en la elaboración de yogurt podría considerarse especialmente relevante. Con este precedente, sería deseable que solo se concedan algunas reivindicaciones de la solicitud de patente, y que las herramientas básicas y fundamentales de tecnología permanezcan en el dominio público en Colombia; esto dependerá -en parte- de que la oficina de patentes haga un examen riguroso de la solicitud y que se diferencie aquello que constituye un mero descubrimiento de aquellos componentes que puedan ser calificados como verdaderas invenciones, para de esta forma mantener el equilibro entre el estímulo o incentivo a la innovación, el acceso a la tecnología y el contrato social que sustenta el sistema de patentes.

\section{EXCEPCIONES A LA PATENTABILIDAD}

La solicitud de patente referida hace alusión a la protección de células germinales, células madre, células de invertebrados, células vegetales, células de animales y células humanas, entre otras, que han sido modificadas genéticamente. Así mismo, se reclama el método para modificar este tipo de células usando la técnica CRISPR/Cas9.

Es por ello que otra de las aproximaciones con que se cuenta para limitar la protección de la tecnología tiene que ver con la excepción existente en la Decisión 486 para las invenciones que van en contra del orden público o la moral, así como las invenciones que van en contra de la salud de personas, animales, vegetales o el medio ambiente. El artículo 20 de la Decisión 486 establece:

Artículo 20.- No serán patentables:

a) las invenciones cuya explotación comercial en el territorio del País Miembro respectivo deba impedirse necesariamente para proteger el orden público o la moral. A estos efectos la explotación comercial de una invención no se considerará contraria al orden público o a la moral sólo debido a la existencia de una disposición legal o administrativa que prohíba o que regule dicha explotación;

b) las invenciones cuya explotación comercial en el País Miembro respectivo deba impedirse necesariamente para proteger la salud o la vida de las personas o de los animales, o para preservar los vegetales o el medio ambiente. A estos efectos la explotación comercial de una invención no se considerará contraria a la salud o la vida de las personas, de los animales, o para la preservación de los vegetales o del medio ambiente sólo por razón de existir una disposición legal o administrativa que prohíba o que regule dicha explotación. 
Este artículo, o más bien su equivalente en la Decisión 344, fue objeto de una interpretación prejudicial del Tribunal de Justicia de la Comunidad Andina (TJCA); en este pronunciamiento el TJCA le da una aplicación muy específica a la excepción de invenciones que van en contra del orden público y la moral, indicando:

Razones de carácter eminentemente ético impiden que el cuerpo humano y aún sus componentes mínimos, como los genes, puedan ser objeto de apropiación exclusiva con fines lucrativos e industriales. Por ello, al momento de interpretar y aplicar a un caso concreto la prohibición de patentar las invenciones sobre materias que componen el cuerpo humano y sobre la identidad genética del mismo, el juzgador o la Oficina Nacional Competente deberán tomar en consideración, de manera prevalente, las implicaciones morales, éticas y de orden público que puedan suscitarse [...]

[...] Pero, no obstante, si el objeto del invento produce una vulneración al orden público o a las buenas costumbres, éste será el principal criterio a ser tenido en cuenta para denegar la patente.

Dentro de la prohibición de patentar materias que componen el cuerpo humano y su identidad genética, se encontrarían comprendidos, por ejemplo, el genoma o germoplasma del ser humano, los procedimientos de mutación o modificación genética, así como otras técnicas que pueden resultar contrarias a la dignidad de la persona o al orden público, tales como clonación de personas, manipulación de embriones humanos o creación en laboratorio de seres humanos individualizados (caso 21-IP-2000, p. 11) (cursivas fuera de texto).

Aunque el documento hace alusión a la Decisión Andina 344 (que era la norma anterior sobre propiedad industrial), en este aspecto la norma no se modificó sustancialmente en la Decisión 486. La Decisión 344, en su artículo 7, rezaba: "7. No serán patentables: a) Las invenciones contrarias al orden público, a la moral o a las buenas costumbres; b) Las invenciones que sean evidentemente contrarias a la salud o a la vida de las personas o de los animales; a la preservación de los vegetales; $\mathrm{o}$, a la preservación del medio ambiente".

Esta interpretación del TJCA fue acogida en la Guía de Examen para solicitudes de patente de invención y modelo de utilidad, emitida por la sic en el año 2012, donde menciona en lo referente a las invenciones exceptuadas de patentabilidad:

Las invenciones cuya explotación comercial debe impedirse para proteger la salud, o la vida de las personas, de los animales o para preservar los vegetales o el medio ambiente. El examinador deberá tener en cuenta por ejemplo los siguientes procedimientos biotecnológicos: 
Procedimientos para modificar la identidad genética de la línea germinal de seres humanos. Por ejemplo: Terapia génica germinal, en la cual la terapia no solo incide en el individuo, sino sobre su descendencia, pues altera o modifica su patrimonio genético.

Uso de embriones humanos para propósitos industriales, o comerciales.

Procesos para modificar la identidad genética de animales que puedan causar sufrimiento al mismo sin un beneficio médico sustancial para el hombre, o para el animal.

\section{$[\ldots]$}

Procedimientos para producir quimeras a partir de células germinales o células totipotenciales de seres humanos y animales (Guía sic, p. 50) (cursivas fuera de texto).

Así mismo, la Guía de la sic se refiere a la materia no considerada invención, indicando con respecto al genoma o germoplasma:

El examinador deberá tener en cuenta que el genoma o germoplasma de cualquier ser vivo natural, incluido el ser humano, no es patentable. Tampoco son patentables los procedimientos de mutación o modificación genética, ni otras técnicas que pueden resultar contrarias a la dignidad de la persona o al orden público, tales como clonación de personas, manipulación de embriones humanos, o creación en laboratorio de seres humanos (Guía sic, p. 49).

Así las cosas, a partir del artículo 20 de la Decisión 486, la interpretación prejudicial 21-IP-2000 del TJCA y la misma Guía sIC, se da una interpretación y limitación muy específica para las invenciones que se consideran contrarias al orden público o la moral, así como a las invenciones que se deban impedir para proteger la salud de cualquier organismo o el medio ambiente.

En sentido similar, la Directiva Europea de Biotecnología 98/44/CE también menciona la patentabilidad de estas mismas invenciones como contrarias al orden público o la moral, en los considerandos 38 y 40, y el artículo 6. En línea con esto, algunas de las oposiciones que radicaron ante la EPO en la solicitud de patente de Feng Zhang sobre el sistema de edición de genes CRISPR/Cas9 en células eucarióticas, hacen alusión al artículo 53 EPC, que se refiere a las excepciones a la patentabilidad por ser invenciones contrarias al orden público y la moral.

Un estudio comparativo ${ }^{5}$ de la OMPI sobre exclusiones de materia patentable permite observar que otros países también excluyen de patentabilidad las modificaciones en línea germinal humana, entre otros: Alemania, Dinamarca, Eslovaquia,

5. омрі, Certain Aspects of National/Regional Patent Laws: (6) Exclusions from Patentable Subject, november 2015 Matter [www.wipo.int/export/sites/www/scp/en/national_laws/exclusions.pdf] En sentido similar: OMPI, scP/13/3. Febrero 4, 2009. "Exclusiones de la materia patentable y excepciones y limitaciones a los derechos conferidos por las patentes", Documento preparado por la Secretaría, en [www.wipo.int/patents/en/topics/exceptions_limitations.html]. 
España, Finlandia, Hungría, Portugal, Suecia. Parte de esas normas se explican por la transposición de la directiva europea, pero en algunos de esos países europeos que no hacen parte de la UE, tales como Albania, Noruega, Serbia, Suiza ${ }^{6}$, pueden existir otras razones históricas y jurídicas. Ciertamente, la bioética incide en la interpretación de las cláusulas de moral y orden público en algunos países (OMPI, 2009). En otros países, como Estados Unidos, no se reconoce esta excepción.

Es discutible si estas normas se enmarcan en teorías del derecho positivistas o de derecho natural. En una de sus acepciones, el positivismo busca que el derecho sea moralmente neutro. En esa medida, las excepciones de patentes que tienen en cuenta la moral y las buenas costumbres podrían catalogarse como iusnaturalistas. Sin embargo, si simplemente se describen normas jurídicas existente y vinculantes -más allá de la opinión que se tenga de ellas- se estaría haciendo un ejercicio de derecho positivo y habría que decir, como Jeremy Benthman, que "la existencia del derecho es una cosa; su mérito o demérito, otra”. En este punto no se estaría ante una interpretación subjetiva y aislada sino ante la descripción del derecho vigente. Aunque ciertamente una opción intermedia sería considerarlas fruto de corrientes "positivistas incluyentes" que aceptan que existen conexiones entre derecho y moral. Un análisis de teoría del derecho excede el objeto de este artículo; además, más allá de las concepciones iusfilosóficas, las nociones de orden público y moral han tenido un desarrollo relativamente autónomo en el derecho de patentes. Con independencia de este comentario teórico, y de las diversas opiniones que puedan existir sobre el tema, lo cierto es que en el derecho colombiano y andino los procedimientos para modificar y las modificaciones a líneas germinales humanas actualmente no serían patentables a la luz de la jurisprudencia del TJCA y de la Guía de Examen de la sic (eso no implica necesariamente que la tecnología no pueda comercializarse, pues, como es bien sabido, la patente no es autorización de comercialización sino una protección jurídica para tener mayor control sobre un producto o un proceso). Además, las reglas establecidas por el Tribunal de Justicia de la Comunidad Andina (TJCA) y la Guía de la sic deberán aplicarse e interpretarse para cada caso concreto atendiendo a las especificidades del mismo. Así como los tribunales nacionales deben aplicar los lineamientos ya establecidos y expresados por los órganos regionales de integración, también deben hacerlo las oficinas de patentes y demás entidades en el marco de sus competencias, pues de otro modo no sería posible alcanzar cierto grado de armonización o uniformidad normativa. Es decir, así como las interpretaciones prejudiciales existentes son obligatorias para los jueces nacionales, también lo son para las autoridades de PI y en consecuencia deben considerarse en los exámenes de patentabilidad; o, en palabras del TJCA, su jurisprudencia "marca la pauta interpretativa"

6. [http://europa.eu/about-eu/countries/index_es.htm], última consulta: 14 de marzo de 2016.

7. Proceso 153-IP-2015, interpretación, ver: [http://intranet.comunidadandina.org/documentos/ Procesos/I_841_153_IP_2015.pdf]. 
Esas pautas las analiza en un primer momento uno o más examinadores de patentes, y las conclusiones del examen se plasman en un acto administrativo, bien de concesión total o parcial, bien o negación de patente, suscrito por el Superintendente de Industria y Comercio a título institucional y susceptible de recurso de reposición en la vía gubernativa y de acción de nulidad ante el Consejo de Estado. Además, esas pautas pueden provenir de pronunciamientos del TJCA originados en solicitudes de jueces nacionales, y también -recientemente- de solicitudes directas de entidades administrativas si cumplen los requisitos para solicitar interpretaciones judiciales "facultativas" establecidas en el proceso 121-IP-2014 que amplió el concepto de "juez nacional" y, bajo ciertas condiciones, lo hizo extensivo a las oficinas nacionales de PI. El alcance de esta figura se desarrolla en dicho pronunciamiento y en los artículos 121 y siguientes del estatuto del Tribunal, y su análisis excede el propósito del presente escrito. Basta indicar que una vez emitida la interpretación judicial es de obligatorio cumplimiento. Se puede especular teóricamente sobre la conveniencia de que los temas de orden público o moral sean analizados por otra instancia, pero eso sería una propuesta conceptual y no la descripción del derecho existente.

Queda claro entonces que las excepciones establecidas en la Decisión 486, esto es, orden público y moral, y salud de organismos y medio ambiente, no son de libre interpretación de la oficina de patentes o sus examinadores, sino que su aplicación debería seguir las pautas aquí mencionadas. Al aplicar las excepciones citadas, se debería entonces limitar o excluir la protección de células germinales y cigotos modificados genéticamente, de origen humano o animal; así como excluir la protección de los métodos para modificar este tipo de células. Esto teniendo en cuenta el régimen legal vigente, sin perjuicio de considerar su revisión y actualización a la luz del potencial y los límites de estas nuevas tecnologías.

Una interpretación similar, aunque no incluida en la interpretación del TJCA, podría darse para la excepción a la patentabilidad de invenciones que afectan la salud de humanos, animales, vegetales o medio ambiente, en las células modificadas por la técnica CRISPR/Cas9 de organismos invertebrados, vertebrados o vegetales. Como ya se mencionó anteriormente, de una parte, está incluida su protección en la solicitud de patente, y por otra, el empleo de la técnica con la aproximación de impulso genético con genes que afectan la viabilidad o equilibrio de la especie compromete directamente la salud de cualquiera de estos organismos o del ambiente. Sin embargo, esta interpretación estaría abierta para la oficina de patentes y su aplicación debería estar mediada por principios tales como el de proporcionalidad Esto implica que las decisiones deben ser proporcionales con el fin perseguido por la excepción.

\section{Consideraciones generales SOBRe RegulaCión en Colombia}

Las múltiples aplicaciones que tiene la tecnología CRISPR/Cas9 hacen que también puedan ser varias las formas de regularla. Mencionaremos aspectos generales a partir del tipo material genético sobre el cual se aplique la tecnología, diferen- 
ciando material genético humano y material genético no-humano, y el uso que se le quiera dar. Aclaramos que lo referente a aspectos regulatorios se tratará con una aproximación general, sin detallar los procedimientos o trámites específicos, puesto que la regulación para cada uno de los tipos de modificación genética en organismos vivos va más allá del alcance de este artículo.

Un aspecto importante de la tecnología es que CRISPR/Cas9 puede realizar modificaciones genéticas sin dejar DNA foráneo en el organismo, lo que puede implicar un cambio en las regulaciones basadas en la presencia de DNA extraño, que es una de las características de las técnicas tradicionales de modificación genética, principalmente en la valoración de plantas genéticamente modificadas (Travis, 2015; Wolt et al., 2015).

\section{Material genÉTico humano}

Esta parte del artículo mostrará, de un lado, el alcance de la regulación administrativo-sanitaria, y de otra parte, las disposiciones penales existentes en materias relacionadas y sus limitaciones.

\section{REGULACIÓN SANITARIA Y DE INVESTIGACIÓN}

En Colombia, la realización de investigación en seres humanos y en embriones, incluida la investigación que realice modificación genética, está reglamentada por la Resolución n. ${ }^{\circ} 8430$ de 1993 del Ministerio de Salud, que establece las normas científicas, técnicas y administrativas para la investigación en salud. En esta resolución se establece que cualquier investigación en salud humana requiere de la aprobación del comité de ética de la institución donde se realiza y del consentimiento informado previo del individuo objeto de investigación, o de los individuos que aportan los genes, para el caso de investigación en embriones y fetos; y además, que se haya realizado una experimentación previa en animales.

Respecto a la investigación utilizando embriones, óbitos o fetos, la resolución no limita el alcance de estas investigaciones por usarse específicamente este tipo de material, únicamente indica que se requiere el consentimiento informado de la mujer y de su compañero, dando la información sobre los posibles riesgos para el embrión, feto o recién nacido (art. 30). Además, se entiende que la investigación debe estar enmarcada o tener acciones que contribuyan:

a) Al conocimiento de los procesos biológicos y sicológicos en los seres humanos; b) Al conocimiento de los vínculos entre las causas de enfermedad, la práctica médica y la estructura social; c) A la prevención y control de los problemas de salud; d) Al conocimiento y evaluación de los efectos nocivos del ambiente en la salud; e) Al estudio de las técnicas y métodos que se recomienden o empleen para la prestación de servicios de salud; f) A la producción de insumos para la salud. 
Todas estas líneas de investigación dejan un espacio abierto para las áreas de aplicación de la técnica de CRISPR/Cas9 en humanos y en embriones. Sin embargo, no hacen diferenciación respecto a la investigación y/o modificación genética en células somáticas, en células germinales o en embriones humanos. Vale resaltar que estos aspectos han sido tratados por autores como Carlos María Romeo Casabona, que ha mencionado algunas condiciones a seguir cuando se realizan estos tipos de investigaciones (Romeo, 2009).

Aunque la resolución incluye en sus artículo 73 y 74 un aparte sobre "la investigación que implique construcción y manejo de ácidos nucleicos recombinantes", la definición dada a los ácidos nucleicos recombinantes restringe a las nuevas combinaciones de material genético obtenidas por fuera de la célula viva y a la inserción de segmentos naturales o sintéticos de ADN. Esto significa que, por una parte, no estarían incluidas las ediciones genéticas que no requieren inserción de material genético, sino que logran reparación del mismo a partir de la copia del gen presente en la misma célula; por otra parte, no está incluida la modificación usando como material genético RNA o vacunas contra virus que usan sondas de RNA viral, siendo todos estos formas de edición genética logradas con la técnica CRISPR/Cas9. Con esto, la resolución no estaría abarcando la investigación con técnicas de edición de genes tales como CRISPR/Cas9, lo que se explica por la relativa antigüedad de dicha resolución que en 2016 cumplirá 23 años y que fue expedida algunos años antes de que se secuenciara el genoma humano.

Obsérvese que hasta aquí no se hace mención a la posibilidad de realizar investigación en línea germinal humana, es decir, no se menciona que se pueda utilizar material biológico de óvulos o espermatozoides con fines de investigación, ni se refiere a este en una etapa antes del embrión. Tampoco se plantea la posibilidad de que la investigación en modificación genética pueda pasar de una generación a otra.

Sin embargo, la resolución también incluye un aparte sobre "Investigación de otros nuevos recursos" que se refiere a "actividades científicas tendientes al estudio de materiales, injertos, trasplantes, prótesis, procedimientos físicos, químicos y quirúrgicos, instrumentos, aparatos, órganos artificiales y otros métodos de prevención, diagnóstico, tratamiento y rehabilitación que se realicen en seres humanos o en sus productos biológicos, excepto los farmacológico"; lo cual podría dar cabida a la investigación con nuevas técnicas de edición de genes, aunque en una interpretación bastante amplia.

Esta resolución, si bien da unas pautas básicas de cómo realizar investigación en salud en humanos, es limitada en dar referenciales éticos de la investigación posible a realizar, lo cual resulta especialmente crítico en el caso de investigación con línea germinal humana o embriones, resaltando la necesidad de que se instituya el Consejo Nacional de Bioética (Rueda y Monsores, 2015), que está pendiente de integrarse de acuerdo a lo dispuesto en la Ley 1374 de 2010. No obstante, en 
octubre de $2015^{[8]}$ y febrero de $2016^{[9]}$ se avanzó consultando un proyecto de decreto "Por el cual se establecen los mecanismos y procedimientos de postulación y selección de los integrantes del Consejo Nacional de Bioética", a través del sitio web de Colciencias.

La existencia de una autoridad en bioética y en investigación en embriones, que autoriza a los investigadores la realización de sus ensayos en embriones o en línea germinal, se puede constatar en otras jurisdicciones: así, en el Reino Unido, con la Autoridad en Fertilización Humana y Embriología (HFEA, por sus siglas en inglés), y en Francia, con el Comité Consultivo Nacional de Ética (CCNE) (CallawaY, 2016). Esto permite que los investigadores tengan una opinión técnico-científica que orienta la realización del ensayo, y que cuenten con instancia que conceptúa en tiempos cortos sobre el tema. Esta figura está pendiente de ser creada en Colombia, y bajo los nuevos mecanismos de edición genética se hace aún más necesaria.

\section{DISPOSICIONES DESDE EL DERECHO PENAL}

Así las cosas, en Colombia, como en la mayoría de países (Ledford, 2015), no existen regulaciones específicas sobre edición de genes en general, ni en humanos. Se tienen unas disposiciones en los artículos 132 a 134 del Código Penal (Ley 599 de 2000) sobre manipulación genética, pero estas no deben entenderse como una regulación completa de la materia, sino que son unas prohibiciones o restricciones de carácter general, teniendo en cuenta que el derecho penal es la ultima ratio o la última instancia a la que se debe acudir para regular conductas humanas. Es decir, los principios de mínima intervención (cfr. Corte Constitucional, sentencias C-365 de 2012 y C-464 de 2014) y de subsidiariedad penal indican que en lo posible los bienes jurídicos deben protegerse a través de otros medios, instituciones, políticas públicas y áreas del derecho, tales como el derecho civil, el derecho administrativo, el derecho sanitario. En sentido similar, el artículo 3. ${ }^{\circ}$ del Código Penal establece los principios de las sanciones penales. Además de ser entendidos como principios generales del derecho penal, la Corte Constitucional también ha hecho alusión a la ultima ratio y la mínima intervención en sentencias sobre salud, bioética y propiedad intelectual, con diversos alcances y conclusiones. Así por ejemplo, en la sentencia que despenalizó el aborto en tres casos (C-355 de 2006), en el fallo que declaró exequible el tipo penal de incesto (C-241 de 2012) y en el fallo que declaró exequible el tipo penal de usurpación de variedades vegetales bajo ciertos entendimientos (C-501 de 2014). Sobre las limitaciones del derecho penal para regular temas de genética, se ha señalado:

8. Consulta 2015: [www.colciencias.gov.co/articulos/consulta-p-blica-consejo-nacionalde-bio-tica].

9. Consulta 2016: [www.colciencias.gov.co/articulos/consulta-p-blica-de-decreto-consejonacional-de-bio-tica]. 
... en el ámbito colombiano, de manera coincidente con buena parte de las otras legislaciones nacionales, la protección ha caído en el ámbito del Derecho Penal, como mecanismo de control social. Pero su efectividad, irreal como puede catalogarse, no ha dado un estándar necesario y lejos está de hacerlo. [...] No es el fenómeno de la inclusión en un tipo de legislación especial el que evitará las conductas contrarias al derecho, sino la posibilidad de hacerse cumplir la misma, y de ello dista totalmente la regulación penal colombiana, con lo cual puede especificarse tres conclusiones de relevancia (Fuentes, 2010).

El Código Penal establece en sus artículos 132 y $134:$

Artículo 132. Manipulación genética. El que manipule genes humanos alterando el genotipo con finalidad diferente al tratamiento, el diagnóstico, o la investigación científica relacionada con ellos en el campo de la biología, la genética y la medicina, orientados a aliviar el sufrimiento o mejorar la salud de la persona y de la humanidad, incurrirá en prisión de uno (1) a cinco (5) años.

Se entiende por tratamiento, diagnóstico, o investigación científica relacionada con ellos en el campo de la biología, la genética y la medicina, cualquiera que se realice con el consentimiento, libre e informado, de la persona de la cual proceden los genes, para el descubrimiento, identificación, prevención y tratamiento de enfermedades o discapacidades genéticas o de influencia genética, así como las taras y endémicas que afecten a una parte considerable de la población.

Artículo 134. Fecundación y tráfico de embriones humanos. El que fecunde óvulos humanos con finalidad diferente a la procreación humana, sin perjuicio de la investigación científica, tratamiento o diagnóstico que tengan una finalidad terapéutica con respecto al ser humano objeto de la investigación, incurrirá en prisión de uno (1) a tres (3) años.

En la misma pena incurrirá el que trafique con gametos, cigotos o embriones humanos, obtenidos de cualquier manera o a cualquier título.

De acuerdo con estos artículos, es posible realizar manipulación genética en humanos cuando el propósito es el tratamiento, diagnóstico o investigación científica, siempre que el propósito sea aliviar el sufrimiento o mejorar la salud de las personas o la humanidad, o una finalidad terapéutica con respecto al embrión (VELAsco, 2012). La prohibición dispuesta en el Código Penal no diferencia con respecto a la técnica de manipulación genética empleada. Así mismo, significa que las modificaciones con propósitos de mejora de características fenotípicas de apariencia o estéticas estarían contempladas como delito (GoNZÁLEZ, 2002).

Una interpretación del significado de manipulación genética en el Código Penal es dada por Carlos Barbosa y Carlos Gómez en los siguientes términos: "En consecuencia, existirá manipulación genética no solo cuando se modifica la herencia 
genética, sino también cuando la misma se transmite por vía diferente a la natural o cuando la conjunción de genes resulta extraña a ella” (BARBosa y Gómez, 2002).

En síntesis, tenemos que, en principio, la investigación con CRISPR/Cas9 en embriones humanos y la modificación genética en células somáticas estaría permitida (o no estaría tipificada) en Colombia, siempre que sea con finalidad terapéutica o diagnóstica dirigida a aliviar el sufrimiento o mejorar la salud, y se tenga el consentimiento informado de la(s) persona(s). No hay menciones en las normas respecto a la investigación en embriones con un desarrollo no mayor a 14 días. De otro lado, la denotación de herencia, implícita en la mención de la modificación del genotipo de la humanidad en la norma, indicaría que no se permite la modificación genética en línea germinal humana con fines diferentes al terapéutico o de diagnóstico (PosAdA, 2015, p. 173), y que la investigación, aunque sea posible, debe estar enmarcada en temas de salud.

El primer filtro para la investigación está dado entonces por una autorregulación que ejercerían los comités de ética de la institución donde se realiza la investigación y que han de ser reconocidos por el Ministerio de Salud.

\section{Material genético No humano}

\section{Normas DE BIOSEgURIDAD}

Colombia es país parte del tratado internacional conocido como Convenio sobre Diversidad Biológica (CDB) de 1992, y también adoptó el Protocolo de Cartagena sobre Seguridad de la Biotecnología del Convenio sobre la Diversidad Biológica, aprobado mediante Ley 740 de 2002.

El Protocolo de Cartagena, en su artículo 3, dispone:

g) Por "organismo vivo modificado" se entiende cualquier organismo vivo que posea una combinación nueva de material genético que se haya obtenido mediante la aplicación de la biotecnología moderna.

h) Por "organismo vivo" se entiende cualquier entidad biológica capaz de transferir o replicar material genético, incluidos los organismos estériles, los virus y los viroides.

i) Por "biotecnología moderna" se entiende la aplicación de:

a. Técnicas in vitro de ácido nucleico, incluidos el ácido desoxirribonucleico (ADN) recombinante y la inyección directa de ácido nucleico en células u orgánulos, o

b. La fusión de células más allá de la familia taxonómica, que superan las barreras fisiológicas naturales de la reproducción o de la recombinación y que no son técnicas utilizadas en la reproducción y selección tradicional. 
Así las cosas, el organismo vivo modificado parece ser entendido como un organismo con una nueva combinación de material genético, pero la introducción de este material o la técnica empleada no está limitada a que el origen del material sea heterólogo, es decir, de otro tipo de organismo. Esto significa que la expresión "nueva combinación de material genético" podría ser entendida como que incluye una combinación que previamente no tenía en su forma natural o no-modificada el organismo, incluidos los organismos modificados por la técnica de CRISPR/Cas9 donde sí se haya introducido DNA de origen heterólogo, dado que en esta aplicación claramente el organismo queda con una nueva combinación de material genético.

Cosa diferente ocurre cuando se realizan con esta técnica modificaciones como el arreglo de un gen donde se repara el DNA, sin tener que incluir ácidos nucleicos de origen heterólogo. En estos casos, aunque el organismo podría tener una nueva combinación de material genético, esta nueva combinación no se ha obtenido de acuerdo con la aplicación de biotecnología moderna, tal como se ha definido en el Protocolo de Cartagena.

Esto, en primer lugar, deja un grupo posible de individuos con modificaciones genéticas y ensayos experimentales sin reglamentación, de acuerdo a lo que se aplica para los Organismos Vivos Modificados (ovm), tal como está ocurriendo en Estados Unidos, donde en el año 2015 se reportaron 10 variedades modificadas genéticamente con nuevas técnicas de edición y que fueron liberadas sin haber seguido el proceso regulatorio de OGM ante el Departamento de Agricultura (USDA) (Самасно et al., 2014; Kuzma, 2016).

De otra parte, el gobierno colombiano, mediante Decreto 4525 de 2005, reglamentó la Ley 740 de 2002, estableciendo el marco regulatorio de los Organismos Vivos Modificados (ovm). En este decreto se establecen las actividades con ovm que implican movimiento transfronterizo, el tránsito, la manipulación y la utilización de los mismos. Además, se establecen las autoridades competentes de acuerdo con el tipo de ovm de que se trate.

Así, se ha definido al Ministerio de Agricultura (art. 4), por conducto del ICA, para ovm de uso agrícola, pecuario, pesquero, plantaciones forestales comerciales y agroindustriales, que puedan tener efectos adversos para la conservación y la utilización sostenible de la diversidad biológica; el Ministerio de Ambiente (art. 5) será la autoridad competente cuando se trate de ovm para uso ambiental; y el Ministerio de Salud, a través del Invima (art. 6), tendrá la competencia cuando se trate de ovm para uso en salud o alimentación humana.

Cada una de las autoridades ha reglamentado sus funciones a este respecto con su propio procedimiento, tema que no será tratado en este trabajo. Pero en principio, se puede decir que las modificaciones genéticas en especies silvestres parecen no tener una reglamentación tan clara, puesto que algunas modificaciones pueden ser entendidas con propósitos de salud humana y al mismo tiempo con efectos ambientales, como es el caso de las modificaciones genéticas realizadas en insectos vectores de enfermedades tropicales. 


\section{NORMAS PARA INVESTIGACIÓN EN ANIMALES}

El uso de animales de laboratorio con fines de experimentación en principio está reglamentado en la Ley 84 de 1989, por la cual se adopta el Estatuto Nacional de Protección de los Animales y que, en lo referente al uso de animales vivos en experimentos e investigación, indica que para toda experimentación con animales vivos se requiere la autorización del Ministerio de Salud. Además, de acuerdo con el artículo 23 de la citada ley, la investigación se realiza:

... sólo cuando tales actos sean imprescindibles para el estudio y avance de la ciencia, siempre y cuando esté demostrado: a) Que los resultados experimentales no puedan obtenerse por otros procedimientos o alternativas; b) Que las experiencias son necesarias para el control, prevención, el diagnóstico o el tratamiento de enfermedades que afecten al hombre o al animal; c) Que los experimentos no puedan ser sustituidos por cultivo de tejidos, modos computarizados, dibujos, películas, fotografías, video u otros procedimientos análogos.

También se indica que se requiere la aprobación de comité de ética (art. 26). En enero de 2016 se expidió la Ley 1774, "Por medio de la cual se modifican el Código Civil, la Ley 84 de 1989, el Código Penal, el Código de Procedimiento Penal y se dictan otras disposiciones". En esta norma, conocida coloquialmente como "Ley contra el maltrato animal", entre otras disposiciones, se establece que los animales son seres sintientes, no cosas, pero no se ocupa específicamente de aspectos de investigación y experimentación con animales.

De otra parte, sentencias del Consejo de Estado han reiterado el carácter fundamental de la libertad de investigación científica (art. 27 superior), pero también las condiciones mínimas en que esta debe realizarse en el caso de animales.

Otra norma relevante es la misma Resolución n. 8430 de 1993 del Ministerio de Salud, que en sus artículos 87 a 93 se refiere a la investigación biomédica con animales. La resolución menciona algunas disposiciones sobre las condiciones para el manejo de los animales y las condiciones de los bioterios, pero no va más allá de lo expresado por la Ley 84 de 1989, indicando que la investigación es necesaria para el control, prevención, el diagnóstico o el tratamiento de enfermedades que afecten al hombre o al animal.

Con lo anterior se aprecia que no hay una delimitación de los protocolos para el mantenimiento de los animales, ni de las consideraciones éticas para la experimentación (Botero y Gómez, 2013). Así como tampoco hay mención de las condiciones para los reportes de resultados de la experimentación, ni del tipo de manipulación genética aprobada con fines de investigación. 


\section{DisPOSICIONES DESDE EL DERECHO PENAL}

Aquí, de nuevo, nos remitimos al Código Penal, para conocer las prohibiciones o restricciones de carácter general que se tienen sobre manipulación genética en especies no humanas. Su artículo 334 dice:

Artículo 334. Experimentación ilegal con especies, agentes biológicos o bioquímicos. El que sin permiso de autoridad competente o con incumplimiento de la normatividad existente, realice experimentos, con especies, agentes biológicos o bioquímicos, que generen o pongan en peligro o riesgo la salud humana o la supervivencia de las especies de la biodiversidad colombiana, incurrirá en prisión de sesenta (60) a ciento cuarenta y cuatro (144) meses y multa de ciento treinta y tres punto treinta tres (133.33) a cincuenta mil (50.000) salarios mínimos mensuales legales vigentes.

Así las cosas, en principio no se deberían realizar modificaciones genéticas en poblaciones silvestres o de plantas y animales de tipo "impulso genético" (gene drive) donde se fije un gen que afecta la supervivencia de los individuos, con miras a no afectar el equilibrio ecológico que pueda acarrear la pérdida o modificación de genes, efectos drásticos sobre la especie, la cadena alimenticia y, en últimas, el equilibrio de un ecosistema, aunque sería posible realizar investigaciones si se cuenta con permiso de autoridad competente y se cumple la normatividad.

\section{CONSIDERACIONES SOBRE INVESTIGACIÓN Y COMERCIALIZACIÓN EN PLANTAS}

En cuanto a plantas cultivables, la pregunta es si los productos obtenidos a partir de CRISPR/Cas9 u otras nuevas técnicas de mejoramiento (NPBT- New plant breeding techniques) están o no sometidos a las regulación de los ogm o transgénicos. En la Unión Europea se creó desde 2007 un grupo para evaluar si las NPBT caen o no dentro del ámbito de la regulación OGM. Inicialmente este grupo está evaluando 8 técnicas, entre las cuales no está CRISPR/Cas9 explícitamente, pero sí la técnica de edición de genes ZFN ${ }^{10}$. Se espera que en el curso de 2016 la Comisión Europea emita una "comunicación interpretativa" sobre si las NPBT deben cumplir la Directiva 2001/18; así los países miembros podrán acogerla o no ${ }^{11}$.

En Francia, por el contrario, el Alto Consejo para la Biotecnología (нсв) -órgano integrado por un Comité Científico (CS) y un Comité Económico, Ético y Social (CEES) (actualmente presidido por la profesora Christine Noiville, de la Universidad París 1)- emitió un documento en febrero de 2016 refiriéndose a las NPBT, en donde se incluye y analiza explícitamente la técnica CRISPR/Cas9. El нСв propone regular

10. [http://ec.europa.eu/food/plant/gmo/legislation/plant_breeding/index_en.htm].

11. Usine Nouvelle, "Ce que pense le Haut conseil des biotechnologies des techniques de l'après-OGM”, en [www.usinenouvelle.com/article/exclusif-ce-que-pense-le-haut-conseil-des-biotechnologies-des-techniques-de-l-apres-ogm.N377441], 4 de febrero de 2016, última consulta: 14 de marzo de 2016. 
estas tecnologías caso por caso. Las empresas próximas al Comité proponen que la regulación se haga con base en las características de cada producto antes que atendiendo las técnicas utilizadas para desarrollarlo. En contraste, varias ONG próximas al Comité Social del нсв consideran que las NPBT deben someterse a las normas de oGM. Ante las diferencias frente a los resultados de los comités, la presidente del нсв ha subrayado "los imperativos que se imponen a las instancias de expertos: pluralismo, debate contradictorio y apertura a la sociedad". Un nuevo documento fue programado para ser emitido en mayo de $2016^{[12]}$.

En Estados Unidos, país más abierto a los ogm que Europa, también se ha discutido si las NPBT, y en particular CRISPR/Cas9, están o no sometidas a las reglas de oGM. Parte de la discusión se ha centrado en establecer si predomina en la regulación a aplicar el procedimiento empleado o las características del producto obtenido; cada enfoque le da prioridad a aspectos diferentes, pero el último permitiría que varios productos modificados por CRISPR/Cas9 y que no se diferencian en su pool genético final de la especie silvestre -porque no se insertan genes heterólogos sino de la misma especie- puedan tener una regulación abreviada, o la que se aplica para las variedades obtenidas por mejoramiento tradicional (Kuzma, 2016).

En Colombia, ya se ha iniciado la discusión sobre el tema, y se plantea por ejemplo tratar las variedades de plantas y animales obtenidas por modificaciones con CRISPR/Cas9, donde se logre fijar una característica deseable proveniente de un gen de la misma especie, como variedades equivalentes a las obtenidas por mejoramiento tradicional, y aplicarles la regulación existente para este tipo de mejoramiento con el objeto de liberar la variedad al medio productivo ${ }^{13}$. Lo anterior, teniendo en cuenta que las plantas o animales obtenidos por un mejoramiento de este tipo no pueden ser diferenciados de aquellos obtenidos por mejoramiento convencional. Específicamente, sobre la regulación de estas variedades plantea Juan Lucas Restrepo, director de Corpoica:

La liberación de cultivos o animales con genes editados no debería regularse de forma distinta a los mejorados por métodos convencionales. Debería ser suficiente si se les exige a quienes investigan y usan las nuevas herramientas genéticas que establezcan protocolos estrictos en sus laboratorios durante las etapas de desarrollo, que demuestren que no hay genes foráneos en las nuevas variedades o animales, que relacionen los genes editados con aquellos que buscan replicar y se encuentran en la naturaleza y las razones para hacerlo, además de exigir calidad y precisión en sus resultados (REstrepo, 2016).

En mayo de 2015 Argentina, de modo pionero, expidió la Resolución 173 de 2015 dirigida a plantas mejoradas ${ }^{14}$, que establece:

12. [www.hautconseildesbiotechnologies.fr/fr/article/mot-presidence].

13. Normativa relacionada: Resolución 946 de 2006 del ICA; Resolución 4254 de 2011 de INVIMA.

14. FAOLEX n. ${ }^{\circ}$ LEX-FAOC144508, en [http://faolex.fao.org/cgi-bin/faolex.exe?rec_id $=144508 \&$ data base=faolex\&search_type=link\&table=result\&lang=eng\&format_name=@ERALL] y [www.infoleg.gob. $\mathrm{ar} /$ infolegInternet/verNorma.do;jsessionid=CA5D4E2E9D93489437D0D42D4BE347D4?id=246978]. 
Artículo $10^{\circ}$ - Establécense los procedimientos para determinar cuándo un cultivo, obtenido a partir de nuevas técnicas de mejoramiento que utilicen técnicas de biotecnología moderna, no se encuentra comprendido en el marco de la Resolución N. 763 de fecha 17 de agosto de 2011 del MiNisterio DE AgRicultura, gaNADERÍa y PESCA y su normativa complementaria.

Así mismo, existen portales de internet dedicados a hacer seguimiento a la regulación de las NPBT o NBT, tales como: NTBplataform ${ }^{15}$ y European Comission-plants ${ }^{16}$.

Las discusiones acerca de la mejor forma de llevar o no llevar a cabo la regulación apenas empiezan para esta tecnología, por lo que los investigadores tendrán que estar atentos a los cambios que se avecinan en temas de regulación para plantas, animales o humanos modificados con la técnica.

\section{Conclusiones}

Si bien las tecnologías de edición de genes en general, y en particular CRISPR/ Cas9, surgen en el ámbito de las biociencias, presentan numerosos retos para el derecho, involucrando sus diferentes ramas: derecho administrativo, derecho sanitario, derecho ambiental, derecho penal, propiedad intelectual, etc. Es decir, si bien es un tema técnico-científico, tiene numerosas implicaciones jurídicas, prácticas y bioéticas.

Los retos jurídicos que supone CRISPR/Cas9, y la edición de genes en general, pueden resolverse parcialmente aplicando principios generales del derecho y algunas normas existentes. Sin embargo, en otros casos se requiere pensar en nuevos instrumentos jurídicos acordes a las características biológicas específicas de esta tecnología. En particular, vale la pena revisar a la luz del estado de la técnica si debe mantenerse la restricción general a la modificación de líneas germinales humanas (Romeo, 2009), considerando que estas restricciones se establecieron jurídicamente cuando no había técnicas que permitían la modificación genética con la precisión que permitiría CRISPR/Cas9. Ante una nueva realidad tecnológica debería el derecho modificarse y actualizarse, sin perjuicio de dar alcance a principios como el de precaución en forma rigurosa y objetiva, cuando así corresponda.

De otra parte, las solicitudes de patente de CRISPR/Cas9, en especial las que recaen en la herramienta como tal, reabren el debate respecto de permitir patentes de amplio alcance sobre técnicas de laboratorio empleadas en todo tipo de investigación. Una alternativa es limitar las posibilidades de que esto sea protegido por propiedad intelectual; otra, que se proteja, pero estableciendo sistemas de licenciamiento amplios y no exclusivos, que permitan que la tecnología se difunda. Esta última opción dependerá siempre de los titulares de la patente. Sin embargo, la

15. мтв Plataform, en [www.nbtplatform.org].

16. European Comission, en [http://ec.europa.eu/food/plant/gmo/legislation/plant_breeding/ index_en.htm]. 
comunidad académica y científica podría mostrar la necesidad de que este tipo de herramientas tengan un licenciamiento amplio, económico y no exclusivo, que permita que la tecnología tenga el mayor impacto posible y el mayor beneficio para la sociedad. Esto es compatible con el estímulo a la investigación y la innovación, pues se reconocerán las verdaderas invenciones, no así con los meros descubrimientos.

Las restricciones a la patentabilidad de invenciones que afectan el orden público y la moral, o la salud de los organismos o el ambiente, tampoco constituyen en sí mismas una regulación completa del tema. Son disposiciones establecidas en el ámbito específico del derecho de patentes y no reemplazan la necesidad de una reglamentación más amplia. Esto teniendo en cuenta que, aunque la invención se considere como que afecta el orden público y la moral o la salud de cualquier organismo, pueden ser utilizadas o comercializadas, y hay independencia entre las autorizaciones sanitarias, las ambientales y las patentes.

Los tipos penales contenidos en los artículos 132 a $134 \mathrm{CP}$ no son suficientes como marco regulatorio, pues son una prohibición y una limitación al uso de la tecnología, pero se requiere una regulación más específica procedimentalmente y más amplia del tema, que establezca una autoridad competente en la materia, y un procedimiento claro y sencillo para pedir la autorización del uso de la tecnología. Esto daría una seguridad jurídica a investigadores, científicos, empresarios, usuarios en general y al mismo Estado.

La reglamentación de una tecnología tan amplia, que abarca la manipulación del genoma humano y de genomas no-humanos, que tiene implicaciones ambientales y en salud, también supone trascender las fronteras de las diferentes subdisciplinas del derecho y tener una mirada más integral, más panorámica de la que pueda tener únicamente el derecho penal, ambiental o la propiedad intelectual. Es necesario tener esta mirada omnicomprensiva para crear una regulación que sea coherente y que no presente contradicciones.

Para abordar estos temas jurídicos, el derecho debe reconocer sus limitaciones y acudir a la experticia de otras disciplinas, tales como la bioética, la medicina, la biología, la agronomía, la sociología, estableciendo un diálogo horizontal con estas áreas. De lo contrario, las regulaciones no serán adecuadas.

Si bien buena parte del debate académico y mediático se ha centrado en la edición de CRISPR/Cas9 en genes y embriones humanos, la tecnología tiene un potencial más amplio, como se indicó, para modificar plantas, animales, microorganismos, los cuales podrían requerir una reglamentación o adaptación específica, tal como ocurre en el ámbito de acceso a recursos genéticos y distribución de beneficios derivados de material biológico, en los cuales hay reglamentaciones diferentes bien sea que se trate de material genético humano o no humano, e incluso alcances diferentes en cuanto a materia patentable en PI.

Más allá de la expedición de normas jurídicas vinculantes o de directrices de derecho blando, se requiere aumentar las capacidades institucionales, jurídicas y técnico-científicas del país para entender, usar y regular esta tecnología. Así como 
crear capacidades y conseguir el fortalecimiento de las instituciones, de manera que sean capaces de poner en práctica esas normas. Esto se puede lograr mediante el desarrollo de la norma que contiene el mandato de crear el Consejo Nacional de Bioética, o por crear grupos de trabajo en el Ministerio de Salud o en el Ministerio de Ambiente, y superando el fetichismo jurídico de creer ingenuamente que basta con expedir normas para cambiar las realidades sociales. Se requiere una institucionalidad que sea capaz de poner en práctica esas normas, tal como ocurre con el HFEA en el Reino Unido, o en Francia con el CCNE en materia humana, y con el нсв en plantas.

Dado el acelerado desarrollo de esta tecnología y de sus modificaciones, con el descubrimiento de variantes de caspasa 9, cualquier regulación que se establezca debería ser lo suficientemente flexible para que se pueda ajustar o actualizar periódicamente a la luz de la evidencia empírica. Tal como ocurre en normas de la Unión Europea y Francia cuando se fijan plazos periódicos para que la autoridad haga un balance y determine la necesidad de la actualización de la norma.

Un ejemplo de esta dinámica regulatoria lo constituye una de las conclusiones del Gene Edit Sumit, donde se dice que por el momento no se recomienda usar la tecnología para modificaciones en línea germinal humana, hasta tanto no se tengan más datos sobre la precisión de la técnica, pero dejando abierta la posibilidad de que en un tiempo corto se replantee a la luz de la evidencia o del nuevo estado de la técnica. Así como esta técnica es dinámica, también deben serlo las normas que la reglamenten, sin perjuicio de respetar los principios fundamentales del derecho y la bioética, como son el consentimiento fundamentado previo y la autonomía y la dignidad de los individuos objeto de modificación genética.

En definitiva, como lo expresó Alexis Verger en twitter, CRISPR/Cas9 es tan poderoso que puede editar su propia historia. Así parece que lo hace, en áreas como variantes biológicas de la herramienta, titularidad de las patentes y regulación aplicable.

\section{REFERENCIAS BIBLIOGRÁFICAS}

Baltimore, D. et al. (19 de marzo de 2015). "A prudent path forward for genomic engineering and germline gene modification", Sciencexpress, Dor: 10.1126/ science.aab1028.

Barbosa, C. A. y Gómez C. A. (2002). Estudio de Bioderecho, Colección de Pensamiento Jurídico n. ${ }^{\circ}$ 5, Derecho Penal, Procuraduría General de la Nación.

Belhaj, K.; Chaparro-García, A.; Kamoun, S.; Patron, N.; Nekrasov, V. (2015). "Editing plant genomes with CRISPR/Cas9", Current Opinion in Biotechnology, vol. 32: 76-84.

Botero, L. y Gómez, R. M. (2013). "Uso de animales de laboratorio en Colombia: reflexiones sobre aspectos normativos y éticos", Rev. Med. Vet. Zoot, vol. 60 (III), septiembre-diciembre: 213-219. 
Callaway, Ewen (2016). "UK scientists gain licence to edit genes in human embryos", Nature, vol. 530 (7588): 18.

Camacho, Alex; Deynze, Allen van; Chi-Ham, Cecilia y Bennett, Alan B. (2014) "Genetically engineered crops that fly under the US regulatory radar", Nature Biotechnology, vol. 32: 1087-1091 Dor:10.1038/nbt.3057.

Chen B., et al. (2013). "Dynamic imaging of genomic loci in living human cells by an optimized CRISPR/Cas system”, Cell, vol. 155: 1479-1491.

Church George (2015). "Encourage the innovators", Nature, vol. 3, diciembre, vol. 528: S7.

Doudna, Jennifer A. y Emmanuelle Charpentier (2014). “The new frontier of genome engineering with CRISPR/Cas9", Science, vol. 346 (6213): DoI: 10.1126.

Doudna, Jennifer (3 de diciembre de 2015). "Embryo editing needs scrutiny", Nature, vol. 528: S6.

Fuentes Contreras, Edgar Hernán (2010). "La manipulación genética en el contexto global y su restricción penal en el ordenamiento jurídico colombiano: perspectivas de la investigación genética y la protección del bien jurídico tutelado", Análisis Internacional, (2): 103-128, disponible en [http://revistas. utadeo.edu.co/index.php/RAI/article/viewFile/19/27].

Gaj, T.; Gersbach, C. A. y Barbas, C. F. (2013). "zFn, talen and Crispr/Casbased methods for genome engineering", Trends in Biotechnology, 31(7): 397 405, [http://doi.org/10.1016/j.tibtech.2013.04.004].

Gantz V.; Jasinskiene, N.; Tatarenkova, O.; Fazekas, A.; Macias, V.; Bier, E. y James A. (2015). "Highly efficient Cas9-mediated gene drive for population modification of the malaria vector mosquito Anopheles stephensi", PNAS, vol. 112 (49): E6736-E6743.

González de Cancino, Emilssen (2002). "El nuevo Código Penal colombiano y la Biotecnología”, Revista de Derecho y Genoma Humano, vol. 16: 107-130.

Granahan, Patricia y Loughran, Chelsea A. (2014). "Crispr/Cas-9: An Exciting Addition to Genomic Editing”, Life Sciences Law \& Industry Report, March, [www.wolfgreenfield.com/files/granahan_and_loughran_crispr_cas9_.pdf].

Hammond, A. et al. (2016). "A CRISPR/Cas9 gene drive system targeting female reproduction in the malaria mosquito vector Anopheles gambiae", Nature Biotechnology, january, vol. 34 (1): 78-83.

Harris, John (2016). "Germline Modification and the Burden of Human Existence”, Cambridge Quarterly of Healthcare Ethics, vol 25: 6-18.

Hsu, P.; Lander, E. y Zhang, F. (2014) "Development and Applications of CRISPR/Cas9 for Genome Engineering”, Cell, vol. 157, June 5: 1262-1278. Hu, W. et al. (2014). "RNA-directed gene editing specifically eradicates latent and prevents new HIV-1 infection", PNAS, vol. 111 (31): 11461-11466. DOI:10.1073/pnas.1405186111. 
JiANG, W. et al. (2013). "Demonstration of CRISPR/Cas9/sgrNA-mediated targeted gene modification in Arabidopsis, tobacco, sorghum and rice", Nucleic Acids Res. 41: e188.

JineK, M. et al. (2012). "A programmable dual-RNA-guided DNA endonuclease in adaptive bacterial immunity", Science, vol. 337: 816-821.

KANG, X. et al. (2016). "Introducing precise genetic modifications into human 3PN embryos by CRISPR/Cas-mediated genome editing", Journal of Assisted Reproduction and Genetics, en [http://dx.doi.org/10.1007/s10815-016-0710-8].

Kirsten, Didi (29 de junio de 2016). "A Scientific Ethical Divide Between China and West", The New York Times, en [www.nytimes.com/2015/06/30/science/ascientific-ethical-divide-between-china-and-west.html?_r=0].

Kuzma, Jennifer (10 de marzo de 2016). "Reboot the debate on genetic engineering", Nature, vol. 531: 165-167.

Lamprea, Natalia y Lizarazo-Cortés, Óscar (marzo de 2015). "Tecnología CRISPR/CAS9 presente y futuro en biotecnología, y controversias de sus patentes", Boletín virtual del Departamento de la Propiedad Intelectual, Universidad Externado de Colombia, en [http://propintel.uexternado.edu.co/tecnologia-crisprcas9-presente-y-futuro-en-biotecnologia-y-controversias-de-sus-patentes/].

Lash, Alex (2014). "Intrigue and Outdated Rules Complicate Big Biotech Patent Fight", PortalXconomy, en [www.xconomy.com/national/2014/12/16/intrigueand-outdated-rules-complicate-big-biotech-patent-fight/].

Lash, Alex (2014). "With Atlas Cash and Berkeley Tools, Intellia Joins the CrISPR Fray", PortalXconomy, en [www.xconomy.com/boston/2014/11/18/with-atlascash-and-berkeley-tools-intellia-joins-the-crispr-fray/].

Lash, Alex y Ready, Aim (2015). "Crispr: Will Gene-Editing Tools Hit Their Targets?", Portal Xconomy, en [www.xconomy.com/national/2015/02/17/ ready-aim-crispr-will-gene-editing-tools-hit-their-targets/].

Ledford, Heidi (2015). "The Landscape for human genome editing”, Nature, vol. 526 (7573): 310.

LIANG, P. et al. (2015). "CRISPR/Cas9-mediated gene editing in human tripronuclear zygotes”, Protein \& Cell, vol. 6(5), 363-372, en [http://doi.org/10.1007/ s13238-015-0153-5].

Long, C. et al. (2014). "Prevention of muscular dystrophy in mice by CRISPR/ Cas9-mediated editing of germline DNA", Science, vol. 345(6201):1184-8.

Makarova K. S. et al. (2011). "Evolution and classification of the Crispr-Cas systems", Nature Rev. Microbiol, vol. 9: 467-477.

Mesa, Jesús (2015). "El descubrimiento del año: la edición de genes para curar enfermedades", El Espectador, 23 de diciembre, en [www.elespectador.com/ noticias/salud/el-descubrimiento-del-ano-edicion-de-genes-curar-enfermarticulo-607467]. 
Mueller, Janice M. (2001). No "Dilettante Affair": Rethinking The Experimental Use Exception to Patent Infringement for Biomedical Research Tools, Washington Law Review Association, vol. 76:1, 2001.

OMPI (4 de febrero de 2009). "scP/13/3. Exclusiones de la materia patentable y excepciones y limitaciones a los derechos conferidos por las patentes", Documento preparado por la Secretaría, en [www.wipo.int/patents/en/topics/ exceptions_limitations.html].

Posada Maya, Ricardo (2015). Delitos contra la vida y la integridad personal, t. II, Bogotá, Universidad de los Andes y Grupo Editorial Ibáñez.

Regalado, Antonio (2014). "El hallazgo biotecnológico del siglo está envuelto en una guerra de patentes", MIT Technology Review, diciembre, en [www.technologyreview.es/read_article.aspx?id=46583].

Restrepo Ibiza, Juan Lucas (16 de marzo de 2016). "Peluquería genética”. Portafolio, en [http://m.portafolio.co/opinion/juan-lucas-restrepo-ibiza/peluqueriagenetica-492703].

Romeo Casabona, Carlos María (2009). Genética, biotecnología y ciencias penales. Bogotá, Universidad Javeriana y Grupo Editorial Ibáñez.

Rueda, Gabriela y Monsores de Sá, Natan (2015). "Impacto de la ausencia del Consejo Nacional de Bioética Colombiano", Revista Latinoamericana de Bioética, vol. 15 (2), 29: 144-155.

SchwANk, G. et al. (2013). "Functional repair of CFTr by CRISPR/Cas9 in intestinal stem cell organoids of cystic fibrosis patients", Cell Stem Cell, vol. 13: 653-658.

Shan, Q.; WANG, Y.; LI, J. y GAO, C. (2014). "Genome editing in rice and wheat using the CRISpr/Cas system", Nat Protoc, vol. 9: 2395-241.

Sherkow, Јасов (2015). "Law, history and lessons in the CRISPR patent conflict", Nature biotechnology, vol. 33 (5): 256-257.

Sherkow, Јасов (2015). “The Crispr Patent Interference Showdown Is On: How Did We Get Here and What Comes Next?", Law and Bioscience blog. Stanford Law School, december 29, en [https://law.stanford.edu/2015/12/29/ the-crispr-patent-interference-showdown-is-on-how-did-we-get-here-andwhat-comes-next/].

Siddique, Haroon (febrero de 2016). "British researchers get green light to genetically modify human embryos". The Guardian, en [www.theguardian. com/science/2016/feb/01/human-embryo-genetic-modify-regulator-greenlight-research].

Sun, Y. et al. (2016). "Engineering Herbicide Resistant Rice Plants through CRISPR/Cas9-mediated Homologous Recombination of the Acetolactate Synthase", Mol Plant, jan 5. pii: S1674-2052(16)00002-2. doi: 10.1016/j. molp.2016.01.001. 
TABebordbar, M. et al. (2015). "In vivo gene editing in dystrophic mouse muscle and muscle stem cells". Science (New York, N.Y.), en [http://science.sciencemag. org/content/early/2015/12/29/science.aad5177].

Travis, John (2015). "Making the cut CRISPR genome-editing technology shows its power", Science, vol. 350 (6267):1456-1457.

Velasco, NANCy (2012). "Manipulación Genética: Análisis científico, ético y legal", Revista Criminalidad, violencia y naturaleza, vol. 47 (08): 30-36.

Wang, T.; Wei, J. J.; Sabatini, D. M. y Lander, E. S. (2014). "Genetic screens in human cells using the CRISPR/Cas9 system”, Science (New York, N.Y.), vol. 343(6166): 80-84, en [http://doi.org/10.1126/science.1246981].

wIPO, SCP, Standing Committee on the Law of Patents Twentieth Session Geneva, january 27 to 31, 2014 Exceptions and Limitations to Patent Rights: Experimental Use And/or Scientific Research Document prepared by the Secretariat [www.wipo.int/edocs/mdocs/patent_policy/en/scp_20/scp_20_4.pdf].

Wolt, J. D.; WANG, K. y YANG, B. (2015). "The regulatory status of genome-edited crops", Plant Biotechnol J. aug 7. doi: 10.1111/pbi.12444.

Wright, A.; NúNEEZ, J. y DoudnA, J. (2016). "Biology and Applications of CRISPR Systems: Harnessing Nature's Toolbox for Genome Engineering”, Cell, vol. 164, January 14: 29-44.

WU, Y. et al. (2013). "Correction of a genetic disease in mouse via use of CRISPRCas9”, Cell Stem Cell, vol. 13, 659-662.

Zhai X, Ng V y Lie R. (2016). "No ethical divide between china and the west in human embryo research", Developing World Bioethics, 1471-8847.

uspto Assignment, en [http://assignment.uspto.gov/\#/search?q=20140068797]. 


\title{
INNOVACIÓN, PORTAL HACIA EL FUTURO
}

\author{
LEONIDAS TORRES CITRARO*
}

\section{PARTE I}

\section{INTRODUCCIÓN}

Quiero imaginarme este ensayo como una batería de argumentos para convencer a cualquier oyente sobre la necesidad y las bondades de la innovación, sobre la obligación de integrarla en nuestro ADN, en nuestra cultura, para beneficio de todos los habitantes del país.

La innovación viene siendo estudiada por economistas, educadores y científicos sociales desde hace más de un siglo, sin embargo es en los últimos cincuenta años que notables investigadores han presentado estudios y teorías concretas sobre su naturaleza e importancia.

Dada las limitaciones del ensayo nos restringiremos a presentar una breve reseña de las teorías de tres grandes economistas como son Joseph A. Schumpeter, Robert Solow y Paul Romer: los tres intentan precisar el peso y la influencia de los frutos del conocimiento, es decir la ciencia, tecnología e innovación en el desarrollo de los países y de las empresas.

\footnotetext{
* Ingeniero industrial (1969) de la Universidad de Mackenzie (Sao Paulo, Brasil) e ingeniero mecánico (1988) de la Universidad Central de Venezuela. Asesor empresarial en las áreas de finanzas, inversiones, mercado de capitales y propiedad intelectual. Profesor del posgrado de Propiedad Intelectual de la Universidad de los Andes (Mérida), Venezuela. Contacto: [leonitor@gmail.com]. Fecha de recepción: 14 de marzo de 2016. Fecha de aceptación: 27 de julio de 2016. Para citar el artículo: Torres Citraro, L. Innovación, portal hacia el futuro. Revista La Propiedad Inmaterial n. ${ }^{\circ} 21$, Universidad Externado de Colombia, enero-junio 2016, pp. 111-137. DOI: http://dx.doi.org/10.18601/16571959. n21.05<.
} 